\title{
Nutrient Needs of Performance Horses
}

\author{
Laurie Lawrence, Ph.D.
}

Department of Animal and Food Sciences

University of Kentucky

Lexington, Kentucky 40546

\begin{abstract}
In 1989, the National Research Council (NRC) Subcommittee on Horse Nutrition defined three categories of exercise: light, moderate or intense. In the $6^{\text {th }}$ revised edition of "The Nutrient Requirements of Horses" (NRC, 2007), there are four categories for exercising horses: light exercise, moderate exercise, heavy exercise and very heavy exercise. Light exercise is described as 1 to 3 hours/week of mostly walking and trotting. Many horses kept for recreational riding would be included in the light exercise category. Moderate exercise consists of 3 to 5 hours/week of mostly trotting with some walking, some cantering and possibly some jumping or other type of more difficult activity. Horses used for horse shows, ranch work and frequent recreational riding would fit into the moderate exercise category. Heavy exercise is described as 4 to 5 hours/week of trotting, cantering, galloping and some jumping, cattle work, etc. Horses engaged in three day eventing, polo, endurance racing or other competitive events would be in this category. The very heavy exercise category includes racehorses and a few other horses that compete at the elite level of endurance or three day eventing.

The NRC (2007) provides recommendations for nutrient intakes by mature exercising horses and for yearlings and two year olds that are receiving regular exercise. Many of the recommendations are similar to those in the 1989 publication, but others have been increased or decreased. For example, crude protein recommendations for exercising horses are generally lower than in the last edition. However, lysine requirements are relatively similar and the publication suggests that protein quality should be emphasized
\end{abstract}

more than in the past. The 2007 NRC contains more information about the factors that influence the requirements for each nutrient, making it easier for users to develop diets for individual horses.

\section{Energy Requirements}

Muscle contraction requires ATP. Only a small amount of ATP is stored in muscle, so any exercise lasting more than a few seconds will require the synthesis of ATP. Fat is an efficient fuel for ATP synthesis. Fat is stored as triglyceride in muscle cells or in fat depots. Only a small amount of fat is stored intramuscularly, so during exercise the fat stored in other locations must be broken down to fatty acids and glycerol for transport to the working muscle. Several hormones regulate the rate of lipolysis including insulin, cortisol and epinephrine. Low insulin and elevated cortisol and epinephrine levels increase the rate of lipolysis, thus enhancing the availability of fatty acids during exercise. If insulin concentrations are elevated in response to a recent meal at the onset of exercise in horses, plasma fatty acid concentrations will be suppressed (Lawrence et al, 1993).

Fat is not the only energy source used during exercise. Carbohydrate is also used to produce ATP. The type of muscle fibers that are used during a specific exercise bout will affect the substrates that are used during that exercise. Muscle fibers in the horse are categorized as: Type I (slow twitch); Type IIA (fast twitch-high oxidative) and Type IIX (fast twitch-high glycolytic). The Type I fibers are usually the most aerobic and prefer fat as a substrate. They are the most fatigue resistant fibers. Type IIA fibers use fat and carbohydrate. The Type IIX fibers are the least aerobic and rely more on carbohydrate as an energy source than 
fat. Type IIX fibers are used during high intensity exercise such as sprinting, when rapid contraction and full force generation are necessary. Because these fibers have lower aerobic capacity, the catabolism of carbohydrate often occurs in a relatively anaerobic environment. The anaerobic catabolism of carbohydrate produces of lactic acid along with ATP. If the muscle fibers generate enough lactic acid, intramuscular $\mathrm{pH}$ will fall, inhibiting muscle contraction and leading to fatigue.

Compared to fat, the amount of carbohydrate stored in the body is small. Carbohydrate is stored as glycogen in the muscle and liver. Muscle and liver glycogen stores can decrease during long term exercise and muscle glycogen can decrease during short term, high intensity exercise. Consequently, the carbohydrate status of exercising horses is quite important. Horses that begin exercise in a glycogen-depleted state may not perform as well as horses that have higher glycogen stores (Lacombe et al., 1999). However, mild glycogen depletion does not always impair exercise performance (Davie et al, 1996).

The NRC (2007) suggests that a $500 \mathrm{~kg}$ horse should receive 20.0, 23.3, 26.6 or 34.5 Mcal of digestible energy (DE) per day for light, moderate, heavy or very heavy exercise, respectively. Most horses in light and moderate exercise will be able to consume 2 to $2.5 \mathrm{~kg}$ of dry matter (DM) for each $100 \mathrm{~kg}$ of body weight. Consequently the DE requirements of horses in light and moderate work can be provided by a diet consisting of good quality forage and a relatively small amount ( 1 to $3 \mathrm{~kg}$ ) of a grain-based concentrate. Horses performing light or moderate exercise will need higher levels of concentrate if the quality or quantity of forage is limited. Higher levels of concentrate will also be needed for horses performing heavy exercise. Horses performing very heavy exercise must be fed high quality forage and large amounts of concentrate or it will be difficult to meet their daily $\mathrm{DE}$ requirement. It is important to feed high quality feeds that are palatable in order to maximize total daily feed intake. A diet containing $6.5 \mathrm{~kg}$ of high quality hay and $6.5 \mathrm{~kg}$ of a grain-based concentrate will provide about $11.7 \mathrm{~kg}$ of dry matter and $35 \mathrm{Mcal}$ of $\mathrm{DE} / \mathrm{d}$. This diet provides approximately $2.3 \mathrm{~kg} \mathrm{DM} / 100 \mathrm{~kg}$ of BW for a $500 \mathrm{~kg}$ horse. If the horse will consume more total feed, the amount of concentrate could be decreased slightly. It is almost impossible to meet the daily DE requirements of race horses if their dry matter intake falls below 2 $\mathrm{kg} / 100 \mathrm{~kg} \mathrm{BW}$. Consequently, it is often challenging to meet the daily DE requirements of horses performing very heavy exercise. When energy requirements are not met, horses will lose weight.

The types of concentrates fed to exercising horses in the U.S. have changed greatly in the last 20 years. These changes have resulted from increased knowledge about the capacity of horses to utilize dietary starch, fat and fiber. Several studies have documented that although total tract starch digestion is very high in the horse, small intestinal starch digestion may be limited (Kienzle et al. 1992; Potter et al., 1992; Radicke, et al., 1991). When starch is digested in the small intestine, the horse receives the maximum energy value from the starch. However, when it escapes digestion in the small intestine, it is fermented to volatile fatty acids in the large intestine, which is not as energetically efficient. In addition, fermentation of starch in the cecum and colon may reduce cecal $\mathrm{pH}$ (Radicke et al., 1991; Willard et al., 1977). Several factors will affect the extent of starch digestion in the small intestine. It appears that oat starch has higher small intestinal digestibility than corn starch, and processing (particularly grinding) can increase small intestinal starch digestibility (Kienzle et al., 1992; Radicke et al., 1991). Therefore, the maximum amount of starch that can be digested by the small intestine is variable. However, many nutritionists now use an upper limit for starch intake in a single meal of $2.0 \mathrm{~g} \mathrm{starch} / \mathrm{kg}$ BW.

Easily digested fiber sources have replaced starch in many commercial concentrates formulated for performance horses. Common fiber sources that are incorporated into concentrates are soy hulls and beet pulp. In addition to being relatively good sources of energy, these feed ingredients are considered to be less disruptive to the microbial population in the large intestine than cereal grains. Fiber sources that are high in pectin (such as beet pulp) also may have enhanced water binding capacity (Warren et al., 1999). When horses consumed diets containing beet pulp, their water consumption was increased. Increased water consumption could have advantages for horses that will experience some dehydration in response to long distance exercise or transportation. 
The equations that use chemical composition to predict DE content of feeds underestimate the energy value of beet pulp and soy hulls (NRC, 2007), but even so, these feed ingredients do not contain as much DE as oats, corn or barley. To increase the energy density of the concentrate, a fat source is often added. At very high inclusion rates, fat may reduce palatability, so many concentrates will contain less than $10 \%$ fat. Vegetable oil is the most common fat source used in horse feeds. Many researchers have investigated whether diets containing supplemental fat can alter the amount of fat and carbohydrate used to synthesize ATP during exercise (Dunnett et al., 2002; Eaton et al., 1995; Hambleton et al., 1980; Hughes et al., 1995; Pagan et al., 1987; Scott et al., 1992). The $6^{\text {th }}$ revised edition of the "Nutrient Requirements of Horses" contains an extensive review of research in this area. It appears that the addition of supplemental fat to the diet may increase the activity of enzymes associated with fat metabolism, thus allowing the horse to increase its ability to use fat as an energy source during exercise (Dunnett, et al., 2002). Some studies have shown that fat supplemented diets spare glycogen utilization, but others have not. It appears that the greatest benefits of fat supplementation have been observed in studies that added supplemental fat to diets that already contained relatively high levels of grain-based concentrates.

Dietary fat is not just an energy source. Lipids are incorporated into cell membranes and are used for the synthesis of a variety of compounds, including some mediators of immunity and inflammation. Equine nutritionists are now examining the effects of dietary fatty acid composition, particularly the role of the n-3 (omega-3) fatty acids on horses (O’Connor, et al., 2004; O'Connor et al., 2007). This is a new research area and specific dietary guidelines are not yet available.

Forage quality is an aspect of performance horse diets that is often overlooked. Horsemen frequently view forage as "filler" and not as an important nutrient source. Consequently they do not provide high quality forage. As noted previously, it is very difficult to meet the DE requirements of horses in very heavy work unless feed intake is high. Hay quality can have a large impact on feed intake. In a study conducted at the University of Kentucky, maximum voluntary consumption of late maturity timothy hay was between 7 and $8 \mathrm{~kg} / \mathrm{d}$ for thoroughbred geldings. However, if they were offered some legume hay (either alfalfa or red clover) they would consume at least 2 more $\mathrm{kg}$ of hay each day. In addition, high quality hay contains more DE than low quality hay. For the horses in our study, the $8 \mathrm{~kg}$ of late maturity timothy hay contained about 13 Mcal of DE. If the horses consumed $10 \mathrm{~kg}$ of alfalfa instead, they would have increased their DE intake by at least $6 \mathrm{Mcal} / \mathrm{d}$ !

\section{Protein and Amino Acid Needs of Exercising Horses}

The protein requirements of the exercising horse have been controversial for some time. In 1978, the NRC indicated that exercising horses required the same amount of protein as a non-exercising horse. This philosophy was abandoned in 1989 when crude protein requirements were increased in proportion to energy intakes. Research on exercising horses between 1989 and 2007 did not support the recommendations of either the 1978 or the 1989 NRC, particularly for horses performing heavy and very heavy exercise. The current crude protein requirements (NRC, 2007) of exercising horses are intermediate to those suggested previously (NRC 1978; 1989). The crude protein requirements in the $6^{\text {th }}$ revised edition of the "Nutrient Requirements of Horses" account for the effects of regular exercise on the accretion of lean body mass and for the loss of protein in sweat. The amount of crude protein needed above maintenance is estimated at approximately 232 $\mathrm{g} / \mathrm{d}$ for a $500 \mathrm{~kg}$ horse receiving heavy exercise and 375 $\mathrm{g} / \mathrm{d}$ for a horse in very heavy exercise (NRC, 2007). It was previously suggested that a $500 \mathrm{~g}$ horse in intense exercise required $656 \mathrm{~g} \mathrm{CP/d}$ above maintenance (NRC, 1989).

Although the recommendations for daily crude protein intakes have been reduced, the NRC (2007) suggests that the diet must contain high quality protein. The estimates of daily crude protein intakes are based on a crude protein digestibility of $79 \%$. In addition, the essential amino acid content of the protein must be relatively high; the crude protein requirements are based on dietary protein that contains at least $4.3 \%$ lysine. If the protein source used in the diet of exercising horses has a lower digestibility or a lower concentration of lysine, then the total amount of crude protein should be increased. 
Diets that contain higher quality protein may have several advantages. By closely matching the amino acids in the diet to the amino acids needed by the horse, the diet will contain less wasted protein that must be excreted. Reducing nitrogen excretion has clear benefits to the environment in many areas. However, reducing the metabolic energy used by the horse to process and excrete extra protein could be an advantage to the horse, particularly if they are already in negative energy balance. Protein catabolism contributes a relatively small proportion of the energy used by for exercise. Leucine may be catabolized for energy, but little is known about the leucine requirements of horses performing different types of exercise.

From a practical standpoint, it may be difficult to formulate diets that meet the DE requirements without exceeding the $\mathrm{CP}$ requirements. Most horses in heavy and very heavy work will have to consume 2 to $2.5 \mathrm{~kg}$ $\mathrm{DM} / 100 \mathrm{~kg} \mathrm{BW}$, to meet DE requirements. A $500 \mathrm{~kg}$ horse receiving heavy exercise requires $862 \mathrm{~g}$ of crude protein, which would result in a dietary crude protein concentration of only 7 to $8.6 \%$ on a DM basis. It is unlikely that a diet containing this amount of protein would provide adequate protein quality. Nutritionists and horse owners should place emphasis on meeting the amino acid requirements of the exercising horse rather than the crude protein requirements. Although the requirements for all amino acids are not known, it is likely that the diet will contain adequate amounts of most amino acids if the requirement for lysine is met.

\section{Vitamin and Mineral Requirements for Exercising Horses}

There has been very little new research on the effect of exercise on the needs of exercising horses for vitamin $A$, vitamin $D$, vitamin $K$, or the $B$ vitamins. Conversely, many researchers have attempted to study oxidative damage during exercise and the effect of dietary antioxidants. Increased oxygen consumption during exercise increases the potential for oxidative damage to cell membranes in the muscle, lungs and other tissues, and could increase the need for vitamin $\mathrm{E}$ or possibly vitamin C. Increasing the levels of these vitamins in the diet can increase the amount of vitamin $\mathrm{E}$ and vitamin $\mathrm{C}$ in the body, but it is not clear whether this conveys an advantage to the horse (NRC, 2007). Horses consuming good quality pasture have been reported to have higher vitamin E status than horses consuming stored feeds (hay and grain), even when the stored feeds were supplemented with vitamin E (Maenpaa et al., 1988a; 1988b). Horses receiving hay and oats did not maintain their vitamin E status during a conditioning program when they were fed an additional $80 \mathrm{IU}$ vitamin E/kg DM (Siciliano, et al., 1997). Vitamin $E$ is a relatively nontoxic nutrient and feeding levels above the current recommendations did not result in negative effects (Siciliano, et al., 1997). When horses do not have access to pasture, it may be prudent to provide vitamin $\mathrm{E}$ in excess of the current recommendations if horses are engaged in regular strenuous activity.

Skeletal integrity is important for the performance horse. Exercise increases bone density and thus may increase the demand for calcium and phosphorus. The current NRC (2007) requirements allow for increased deposition of calcium and phosphorus in bone. The daily calcium intakes recommended for horses in moderate, heavy and very heavy exercise (NRC, 2007) are similar to previous recommendations (NRC, 1989). However, the recommendations for horses in light exercise are somewhat higher than the previous recommendation. Although the current NRC (2007) increases calcium and phosphorus intakes for mature horses receiving light exercise, it did not do the same for two year old horses that are receiving light exercise. The NRC (2007) calculates the calcium and phosphorus requirements of two year old horses from body weight and average daily gain. The daily calcium and phosphorus requirements for a 2 year old (all levels of work) with an expected mature weight of $500 \mathrm{~kg}$ are $36.7 \mathrm{~g} / \mathrm{d}$ and $20.4 \mathrm{~g} / \mathrm{d}$, respectively (NRC, 2007). The previous recommendations were $24 \mathrm{~g}$ of calcium and $13 \mathrm{~g}$ of phosphorus, for 2 year olds not in training and $34 \mathrm{~g}$ calcium and $19 \mathrm{~g}$ of phosphorus, for two year olds in training. Although the new recommendations do not make allowances for level of training in 2 year olds, the base levels of calcium and phosphorus are much higher than in the previous publication. The NRC (2007) suggests that the levels of calcium and phosphorus for two year old horses should be adequate for growth and for increased mineral deposition in response to exercise. 
The effect of exercise on electrolyte and fluid balance in horses has received significant attention from researchers in the last two decades. The daily electrolyte requirements of exercising horses can be estimated as the sum of the dietary electrolytes needed for maintenance and those needed to replace sweat losses. The mineral composition of sweat has been described by several authors, and the amount of sweat lost in various events has been estimated. The NRC (2007) suggested that $3.1 \mathrm{~g}$ of dietary sodium and $5.3 \mathrm{~g}$ of dietary chlorine would be needed to replace the amounts of these minerals lost in one liter of sweat. The potassium requirement above maintenance was estimated using a potassium concentration in sweat of $1.4 \mathrm{~g} / \mathrm{l}$ and an absorption coefficient of $50 \%$. Daily sweat losses were estimated as $0.25 \%, 0.5 \%, 1 \%$ and $2 \%$ of body weight for light, moderate, heavy and very heavy exercise, respectively. In application, these estimates should be adjusted for the effects of ambient temperature on sweating rate. It is likely that these sweating rates are too high for cool environments.

\section{References}

Davie A.J., D.L. Hodgson, D.R. Hodgson and R.J. Rose. 1996. Effects of glycogen depletion on high intensity exercise performance and glycogen utilisation rates. Pferdeheilkunde $12: 482$

Dunnett, C.E., D.J. Marlin and R.C. Harris. 2002. Effect of dietarly lipid on response to exercise: relationship to metabolic adaptation. Equine Vet. J. Suppl. 34:75-80.

Eaton M.D., D.R. Hodgson, D.L. Evans, W.L. Bryden and R.J. Rose. 1995. Effect of diet containing supplementary fat on the capacity for high intensity exercise. Equine Vet Journal 18: (supplement):353

Hambleton P.L., L.M. Slade, D.W. Hamar, E.W. Kienholz and L.D. Lewis. 1980. Dietary fat and exercise conditioning effect on metabolic parameters in the horse. J. Anim. Sci. 51:1330

Hintz, HF, M. Ross, F. Lesser, P.F. Leids, K.K. White, J.E. Lowe, C.E. Short and H.F. Schryver. 1977. Dietary fat for working horses. Proceedings of the Cornell Nutrition Conference, p87

Hughes S.J., G.D. Potter, L.W. Greene, T.W. Odom, M. MurrayGerzick. 1995. Adaptation of thoroughbred horses in training to a fat supplemented diet. Equine Vet J. 18(supplement):349

Kienzle E., S. Radicke, S. Wilke, E. Landes and H. Meyer. 1992. Praeileal starch digestion in relation to source and preparation of starch. Pferdeheilkunde (1st European Conference on Horse Nutrition): 103
Lacombe V., K.W. Hinchcliff, R.J. Geor and M.J. Lauderdale. 1999. Exercise that induces substantial muscle glycogen depletion impairs subsequent anaerobic capacity. Equine Vet J. (Supplement 30):293

Lawrence L.M., L.V. Soderholm, A. Roberts, J. Williams and H. Hintz. 1993. Feeding status affects glucose metabolism in exercising horses. J. Nutr. 123:2152

Maenpa, P.H., T. Koskinen and E. Koskinen. 1988a. Serum profiles of vitamins $\mathrm{A}, \mathrm{D}$ and $\mathrm{E}$ in mares and foals during different seasons. J. Anim Sci. 66:1418

Maenpa, P.H., A. Pirhonen and E. Koskinen. 1988b. Vitamin A, D and $\mathrm{E}$ nutrition in mares and foals during the winter season: effect of feeding two different vitamin-mineral concentrates. J. Anim Sci 66:1424

NRC. 1978. The Nutrient Requirements of Horses, 4th revised edition. National Academy Press, Washington DC.

NRC. 1989. The Nutrient Requirements of Horses, 5th revised edition. National Academy Press, Washington DC.

NRC. 2007. The Nutrient Requirements of Horses, 6th revised edition. National Academy Press, Washington DC.

O’Connor, C.I., L.M. Lawrence, A.C. St. Lawrence, K.M. Janicki, L.K., Warren and S. Hayes. 2004. The effect of dietary fish oil supplementation on exercising horses. J. anim. Sci. 82:2978

O’Connor, C.I., L.M. Lawrence and S.H. Hayes. 2007. Dietary fish oil affects serum fatty acid concentrations in horses. J. Anim. Sci. 85:2183

Pagan J.D., B. Essen-Gustavsson, A. Lindhome, and J. Thornton. 1987. The effect of dietary energy source on exercise performance of standardbred horses. Equine Exercise Physiology II:686

Potter G.D., F.F. Arnold, D.D. Householder, D.H. Hansen and K.M. Brown. 1992. Digestion of starch in the small or large intestine of the equine. Pferdeheilkunde (1st European Conference on Horse Nutrition): 107

Radicke S., E. Kienzle and H. Meyer. 1991. Preileal apparent digestibility of oats and corn starch and consequences for cecal metabolism. Proceedings Equine Nutrition and Physiology Symposium, p43

Scott, B.D., G.D. Potter, L.W. Greene, P.S. Harris and J.G. Anderson. 1992. Efficacy of a fat supplemented diet on muscle glycogen concentrations in exercising thoroughbred horses maintained in varying body conditions. J. Equine Vet Science. 12:109

Siciliano, P.D., A.L. Parker and L.M. Lawrence. 1997. Effect of dietary vitamin $\mathrm{E}$ supplementation on the integrity of skeletal muscle in exercised horses. J. Anim Sci. 75:1553.

Warren L.K, L.M. Lawrence, T. Brewster-Barnes and D.M Powell. 1999. The effect of dietary fibre on hydration status after dehydration with frusemide. Equine Vet J (supplement 30):508

Willard, J.G., J.C. Willard, S.A. Wolfram and J. P. Baker. 1977. Effect of diet on cecal $\mathrm{pH}$ and feeding behavior of horses. J. Anim. Sci. 45:87 